\title{
Family Medicine Across the Globe: Developing Effective Solutions
}

\author{
Joshua Freeman, MD
}

(Fam Med. 2018;50(6):417-9.)

doi: 10.22454/FamMed.2018.768617

$\mathbf{T}$ he discipline of family medicine, based on the attributes of continuity, comprehensiveness, accessibility, care coordination, and care in the family and community context, best represents the combination of values, skills, and training needed to be the central component of a nation's health care system. This is not only the opinion of family doctors, but also the conclusion reached by most health policy experts, including the World Health Organization (WHO), the National Academy of Medicine, the Commonwealth Fund, and others..$^{1-3}$ Barbara Starfield and other researchers have demonstrated that countries with highly effective health systems and excellent health outcomes-including Canada and most of Western Europe - are built around family physicians (also known as general practitioners or GPs). ${ }^{4-6}$ Countries in which the health system has an inadequate core of family physicians have, overall, higher costs, poorer access, and worse population-based health outcomes. Most of these are less-developed countries, with the notable exception of the United States. The United States is both the wealthiest country in the world and the one that spends the most on medical care (both by total and per capita measures), but it has far worse health outcomes than other wealthy countries. Indeed, the US-based Patient-Centered Primary Care Collaborative (PCPCC), citing many of the same sources referenced above, ${ }^{7}$ was established by US-based multinational corporations that attributed the fact that their health costs in other countries were far less than in the
United States to the absence of an adequate primary care base (rather than the absence of a national health system since, after all, their employees were privately insured). ${ }^{8}$

In this issue of Family Medicine, Rouleau, Bourget, Chege, and colleagues examine the development of family medicine in seven countries across the globe: Brazil, Canada, Ethiopia, Haiti, Indonesia, Kenya, and Mali. ${ }^{9}$ The authors, representing all seven countries, use a case-study methodology based on the theories of appreciative inquiry and complexity to identify both enablers of and barriers to the discipline's development in each of these countries, and to draw summary conclusions about what these are likely to be in any country that seeks to develop or increase its production of family physicians. Because the countries studied are located in the Americas, Africa, and Asia, and range from among the poorest (Haiti) to among the wealthiest (Canada), and also include two of the world's five most populous nations (Indonesia and Brazil), the conclusions are likely to be quite generalizable.

The four "meta-enablers," identified by the authors as present in all seven case studies, were: (1) the presence of effective champions to act as catalysts and facilitators and to "broker critical ties;" (2) committed partnerships with both other specialties and influential national and financial leaders; (3) the political will, and consequent health policy objectives, aimed at effectively addressing the most pressing health needs of a country, along with taking advantage of "policy windows;" and (4) an 
adaptability in defining the role of family medicine in a given setting. The barriers were, unsurprisingly, the absence of (or loss of existing) enablers, and included loss of a key champion, resistance from other specialties, and poor programs or planning within family medicine itself. Also unsurprisingly, the individual case studies demonstrate that all politics is local and, as frustrating as it may be to those focused on maximizing the public's health, a nation's health system is very political at both the government and medical practitioner level.

One strength of family medicine that the article emphasizes is its greater utility, compared to other specialties, in providing health care in rural areas and in poor parts of cities in the countries studied. While also true in developed countries such as the United States and Canada, it is especially important in countries where rural and poor people make up a majority of the population, including six of the seven countries studied.

This is a double-edged sword. Family medicine advocates are proud of the discipline's ability to provide comprehensive care in rural areas. For example, the National Health Service Corps in the United States identified long ago that sending an internist, pediatrician, and OB-GYN to a rural community meant that they were all on call every day, while three family physicians could share call. Many are also proud of their commitment to the health of economically underserved communities. However, the converse implication is that specialist and subspecialist care is better, when it is available, for wealthier people in urban areas, a conclusion family medicine would take issue with. Of course, even in poor countries, policy makers are overwhelmingly urban and high-income, and often wish to ensure that there is a glittering, subspecialtybased academic medical center in the capital (to which they can go for care). Advocating for care for the poor majority is easier than actually providing it.

Another aspect of this same attitude is the resistance of specialists to the expansion of family medicine, described by the authors in this study as a barrier, and also often seen in developed countries such as the United States. This becomes most apparent when family physicians are perceived as threatening to move out of their niche in rural and poor areas to more urban and well-to-do areas, and thus potentially threaten the income of, and even need for, other specialists. What makes the most sense is a national system based on family physicians providing the bulk of health care in both rural and urban, and rich and poor communities, with a regional and national referral system for those needing more specialized medical or surgical management. However, implementation of such a strategy in the real world is confronted with all of the barriers that the authors identify.

On the positive side, the paper makes clear that one of the key strengths of family medicine is that its breadth is mirrored by its adaptability and flexibility in meeting the specific needs of both different countries and the regional and local areas within them. Of course, the deployment of a large cohort of well-trained family physicians requires the ability to effectively train them, and this capacity must be developed concomitantly with the health system that will provide them with practice opportunities when they complete their training. Flexibility cannot extend to abandoning the discipline's core attributes of continuity, comprehensiveness, accessibility, care coordination, and care in the family and community context, for without these it would no longer be family medicine, and would not be likely to achieve the health outcomes it otherwise could.

Each country and region described by the authors has a different set of circumstances to navigate, but all also have the same basic need to deliver high-quality, cost-effective care to their populations. We should not be in the business of marketing the specialty of family medicine because it is ours. This makes us no different than the other self-serving special interests in health care. When the goal of the health system is to maximize the health benefit to the population rather than the income of doctors, hospitals, drug and device manufacturers, and insurers, then increasing the supply of and deployment of family medicine is likely to be the most successful choice. There is nothing new about this, but we still have a long way to go in making this goal a reality.

CORRESPONDENCE: Address correspondence to $\mathrm{Dr}$ Freeman at jfreeman@kumc.edu.

\section{References}

1. World Health Organization. The World Health Report 2008 - Primary Health Care (Now More Than Ever). http://www. who.int/whr/2008/en/. Accessed April 23, 2018. 
2. Institute of Medicine. Defining Primary Care: An Interim Report. Washington, DC: National Academies Press; 1994. https://www.nap.edu/read/9153/. Accessed April 23, 2018.

3. Kiszla J, Nuzum R. The value of strong primary care. Commonwealth Fund; 2013. http://www.commonwealthfund.org/ publications/blog/2013/may/the-value-of-strong-primary-care. Accessed April 23, 2018.

4. Shi L, Starfield B, Politzer R, Regan J. Primary care, self-rated health, and reductions in social disparities in health. Health Serv Res. 2002;37(3):529-550.

5. Macinko J, Starfield B, Shi L. The contribution of primary care systems to health outcomes within Organization for Economic Cooperation and Development (OECD) countries, 1970-1998. Health Serv Res. 2003;38(3):831-865.
6. Starfield B, Shi L, Macinko J. Contribution of primary care to health systems and health. Milbank Q. 2005;83(3):457502. Patient Centered Primary Care Collaborative, "Shared Principles." https://www.pcpcc.org/about/shared-principles.

7. Patient-Centered Primary Care Collaborative. Shared Principles. https://www.pcpcc.org/about/shared-principles. Accessed April 23, 2018.

8. Patient-Centered Primary Care Collaborative. About Us. https://www.pcpcc.org/about. Accessed April 23, 2018.

9. Rouleau K, Bourget M, Chege P, et al., Strengthening primary care through family medicine around the world: collaborating toward promising practices. Fam Med. 2018;50(6)426436.

\section{Family Medicine Call for Submissions: The Outcomes of Family Medicine for America's Health}

The Family Medicine for America's Health (FMAHealth) Board of Directors and the journal Family Medicine announce our intention to publish a theme issue of Family Medicine to highlight the lessons learned and accomplishments of FMAHealth's 5-year collaborative effort to drive improvement in American health care, demonstrate the value of primary care, and reform the specialty of family medicine. The purpose of the theme issue will be to provide an assessment of the project and to update the journal's readers about FMAHealth's progress in achieving its goals.

Papers for the theme issue will be considered if they are submitted to the journal by July 1 , 2018. All submissions should comply with the journal's Instructions for Authors and must be submitted into the journal's electronic manuscript management system. Further details regarding submission requirements, and types of articles sought, can be found at https://journals.stfm.org/media/1367/ fmahealth-call-for-papers.pdf. 